\title{
Dyspeptic symptoms in patients with type 1 diabetes: endoscopic findings, Helicobacter pylori infection, and associations with metabolic control, mood disorders and nutritional factors
}

Mariza Faria', Elizabeth João Pavin², Maria Cândida Ribeiro Parisi², Cristiane Kibune Nagasako ${ }^{3}$, Maria Aparecida Mesquita'

\begin{abstract}
Objectives: To evaluate, in a group of patients with long-standing type 1 diabetes (DM1), an association of dyspepsia symptoms with: changes in the gastroduodenal mucosa, infection by Helicobacter pylori, glycemic control, and psychological and nutritional factors. Subjects and methods: A total of 32 patient with DM1 were studied (age: $38 \pm 9$ years; females: 25 ; diabetes duration: $22 \pm 5$ years). All patients answered a standardized questionnaire for the evaluation of gastrointestinal symptoms and underwent upper gastrointestinal endoscopy, with gastric biopsies for the evaluation of Helicobacter pylori infection. The presence of anxiety and depression was evaluated by the HAD scale. Nutritional parameters were BMI, arm and waist circumference, skinfold measurement, and body fat percentage. Results: Upper endoscopy detected lesions in the gastric mucosa in $34.4 \%$ of the patients, with similar frequency in those with $(n=21)$ and without dyspepsia $(n=11)$. The patients with dyspepsia complaints showed greater frequency of depression $(60 \%$ vs. $0 \% ; \mathrm{p}=0.001)$, higher values for HbA1c (9.6 \pm 1.7 vs. $8.2 \pm 1.3 \% ; p=0.01)$ and lower values for BMI $\left(24.3 \pm 4.1\right.$ vs. $\left.27.2 \pm 2.6 \mathrm{~kg} / \mathrm{m}^{2} ; \mathrm{p}=0.02\right)$, body fat percentage $(26.6 \pm 6.2$ vs. $30.8 \pm 7.7 \% ; p=0.04)$, and waist circumference $(78.7 \pm 8$ vs. $85.8 \pm$ $8.1 \mathrm{~cm} ; \mathrm{p}=0.02$ ). No association was found between the symptoms and the presence of Helicobacter pylori. Conclusions: Dyspepsia symptoms in patients with long-standing DM1 were associated with glycemic control and depression, and they seem to negatively influence the nutritional status of these patients. Arch Endocrinol Metab. 2015;59(2):129-36
\end{abstract}

Keywords

Type 1 diabetes; dyspepsia; anxiety; nutrition
1 Gastroenterology Division, Department of Clinical Medicine, Faculty of Medical Sciences, State University of Campinas (FCM/ Unicamp), Campinas, SP, Brazil ${ }^{2}$ Endocrinology Division, Department of Clinical Medicine, FCM/Unicamp, Campinas, SP, Brazil ${ }^{3}$ Gastrocenter, Unicamp, Campinas, SP, Brazil

Correspondência para: Maria Aparecida Mesquita Departamento de Clínica Médica, Faculdade de Ciências Médicas, Universidade Estadual de Campinas Rua Tessália Vieira de Camargo, 126 13083-887 - Campinas, SP, Brasil mesquita@fcm.unicamp.br m.aparecida.mesquita@gmail.com

Received on June/24/2014 Accepted on Dec/3/2014

DOI: 10.1590/2359-3997000000025

\section{INTRODUCTION}

$\mathrm{R}$ ecent studies indicate that the prevalence of gastrointestinal symptoms in patients with type 1 diabetes (DMl) is greater than that observed in the overall population (1-3). It was also demonstrated that this clinical picture has a negative impact in the quality of life of these patients (4). However, the mechanisms responsible for digestive manifestations in diabetes have not been elucidated, yet (5).

Few authors have used upper digestive endoscopy (UDE) to analyze the presence of mucosal lesions that could explain the esophageal and dyspeptic complaints in diabetic patients. In one study, endoscopic evaluation showed that the lesions in the esophagogastric mucosa were more frequent in diabetic patients (most of them with type 2 diabetes) than in non-diabetic controls. However, no relationship was observed between the lesions found and the presence of digestive symptoms (6). On the other hand, some authors observed a similar frequency of endoscopic lesions in diabetic and non-diabetic control patients (7).

Studies that investigated the relationship between digestive symptoms and Helicobacter pylori infection (8), glycemic control $(1,9)$, and abnormal autonomic function $(5)$ in diabetes also showed contradictory results. Besides, no direct relationship was demonstrated between diabetic gastroparesis and specific digestive symptoms $(10,11)$. 
The association between gastrointestinal symptoms and psychological factors, particularly anxiety and depression, is growingly recognized in the literature since the studies which were carried out in patients with functional diseases, such as functional dyspepsia and irritable bowel syndrome (12). There is evidence of increased prevalence of anxiety and depression in diabetic patients $(13,14)$, but the relationship between these disorders and the presence of gastrointestinal symptoms have seldom been investigated in diabetes. An Australian study that evaluated both type 1 and type 2 diabetes patients demonstrated that digestive symptoms were twice more frequent in those patients that showed anxiety and/or depression (15). This information indicates the need for new studies to confirm this relationship in patients with DMl. Besides, there are no studies involving the possible influence of dyspeptic symptoms in the nutritional picture of patients with DMl.

Therefore, the objectives of this study were to evaluate, in a group of patients with long-term DMl, the relationship between dyspeptic symptoms with the following factors: changes in the gastroduodenal mucosa; infection by Helicobacter pylori; glycemic control; and psychological and nutritional factors.

\section{SUBJECTS AND METHODS}

A total of 32 patients with DMl were seen at the DMl outpatient clinic of the Endocrinology Division at the Hospital das Clínicas da Unicamp (HC-Unicamp). Mean age of the participants in the study was $38 \pm 9$ years, with $25(78.1 \%)$ female patients and 7 (21.9\%) male ones. $\mathrm{DMl}$ diagnosis was determined by the criteria of the American Diabetes Association (ADA) (16).

Inclusion criteria were: patients had to be older than 18 years of age, diabetes diagnosis should have been established more than 10 years before, written consent for upper digestive endoscopy (UDE). Exclusion criteria were: pregnancy, previous gastrointestinal tract surgery, renal failure with dialysis, concurrent diseases that may cause changes in gastrointestinal motility.

The control group for the presence of gastrointestinal symptoms was made up by 50 healthy volunteers (30 women and 20 men, aged $33 \pm 8$ years) recruited among employees and students at the HC and Gastrocentro-Unicamp. The control group was matched to the patient group based on age, sex and BMI. None of the volunteers had cardiac or gastrointestinal disease, arterial hypertension, diabetes or previous abdominal surgery.
This study was approved by the Research Ethics Committee at Unicamp. All participants signed a written informed consent term.

\section{Clinical and laboratory assessment}

Factors related to DMl, including duration of the disease, chronic complications (retinopathy, peripheral neuropathy, and diabetic nephropathy), and laboratory parameters, including fasting glucose, urea, creatinine, creatinine clearance, and TSH were obtained from patient records. Glycemic control was analyzed by means of glycated hemoglobin (HbAlc) obtained by high efficiency liquid chromatography. Levels above $7 \%$ were considered inadequate glycemic control.

Diabetic retinopathy was diagnosed by fundoscopy carried out by an ophthalmologist at HC-Unicamp. Diabetic nephropathy was evaluated by means of microalbuminuria in a morning urine sample; nephropathy was considered when two values observed on two different days were above the normal value (up to $30 \mathrm{mg} / \mathrm{g}$ creatinine), in the absence of urinary infection. The diagnosis of peripheral neuropathy was determined using a $10 \mathrm{~g}$-monofilament for pain sensation, $128 \mathrm{~Hz}$ tuning fork for vibration perception, assessment of achilles and patellar reflexes, as well as palpation of dorsalis pedis and posterior tibial pulses.

\section{Gastrointestinal symptoms}

Gastrointestinal symptoms were analyzed in patients and controls using a standardized questionnaire that was previously validated (17). The following esophageal symptoms were analyzed: dysphagia, heartburn and regurgitation. Dyspeptic symptoms included pain or epigastric burning, postprandial bloating, nausea, and vomiting. Intestinal symptoms analyzed were: abdominal distention, abdominal pain, constipation, diarrhea, and fecal incontinence. Each symptom received a score from 0 to 4 , according to the intensity, as follows: $0=$ no symptom, 1 = mild (symptoms can be ignored),

2 = moderate (symptoms cannot be ignored, but do not influence daily activities), 3 = severe (symptoms influence daily activities). Only moderate or severe symptoms that occurred more than once a week were considered in the analysis of the data.

\section{Upper digestive endoscopy}

Upper digestive endoscopy was carried out in order to diagnose gastroduodenal lesions responsible for gastro- 
intestinal symptoms. Besides, gastric biopsy fragments were collected for $H$. pylori analysis (body and antrum) and fragments of the bulb and postbulbar portion (distal to the duodenal papilla) were collected to the analysis of celiac disease.

\section{Analysis of $\mathrm{H}$. pylori infection}

Analysis of $H$. pylori was carried out by the urease test and histological examination of fragments collected in the endoscopy. Infection was considered to be negative when both tests were negative.

\section{Diagnosis of celiac disease}

Considering the increased prevalence of celiac disease in DMl (18), and the possible nutritional changes caused by this comorbidity, the presence of celiac disease in the patient group was analyzed by means of histological examination of duodenal biopsies.

\section{Assessment of mood disturbances by the HAD scale}

The presence of anxiety and depression was evaluated using the Portuguese version of the HAD (Hospital Anxiety and Depression) scale, which was validated in Brazil (19). This scale is divided into subscales for anxiety and depression, and values over 8 in each subscale indicate anxiety or depression.

\section{Assessment of nutritional status}

Nutritional status of the patients was assessed according to standardized protocols (20) that yielded the following anthropometric indices: body mass index (BMI), calculated as weight $(\mathrm{kg}) /$ height $^{2}(\mathrm{~m})$; arm circumference (AC); corrected arm muscle area (cAMA); waist circumference (WC); and skinfold measurements: tricipital (TSF), bicipital (BSF), subscapular (SSSF) and suprailiac (SISF). Body fat percentage was calculated based on these indices. Measurement of arm and waist circumferences were carried out with an inextensible tape, and skinfolds were measured with a Lange caliper (Cambridge Scientific Industries Cambridge, MA) with $0.2 \mathrm{~mm}$ accuracy.

\section{Statistical analysis}

Results were expressed as means \pm SD. Statistical analysis was carried out using the Mann-Whitney, Chi-Square and Fischer Exact Test, as necessary. The comparison between multiple variables was carried out by the analysis of variance (ANOVA) and Tukey test. Correlation analysis was carried out using Spearman correlation coefficient. Statistical significance was set at $\mathrm{p}<0.05$.

\section{RESULTS}

\section{Clinical and demographic characteristics of the patients}

Table 1 shows the main demographic and clinical characteristics of the 32 patients with DMl. Mean time from diagnosis was $22 \pm 5$ years.

All patients used insulin, and none of them was under treatment with metformin. Peripheral neuropathy was found in $46.9 \%$ of the participants. Mean HbAlc was $9.1 \pm 1.7 \%$, indicating that the group of patients studied had inadequate glycemic control. Only one patient $(3 \%)$ showed good control, with $\mathrm{HbAlc}<7 \%$. There were no significant differences $(\mathrm{p}>0.05)$ between men and women in relation to the clinical parameters.

\section{Gastrointestinal symptoms}

Table 2 shows the frequency of the different gastrointestinal symptoms reported by diabetic patients and the control group. Compared with the control group, diabetic patients presented significantly greater frequencies of dysphagia, heartburn, regurgitation, postprandial bloating, nausea, vomiting, and intestinal symptoms (constipation, diarrhea, abdominal distention, and fecal incontinence).

Considering the group of symptoms, it was observed that $21(65.6 \%)$ of the patients showed dyspepsia. The main dyspepsia complaint was postprandial fullness more than three times a week in all cases. In patients with dyspepsia, 7 (33.3\%) presented symptoms associated with gastroesophageal reflux (heartburn and/or regurgitation) and 18 (85.7\%) showed associated intestinal complaints, such as constipation, diarrhea, pain or abdominal distention. None of the patients presented with exclusively reflux symptoms, and none of them used gastric acid secretion inhibitors or prokinetic drugs in the treatment of the symptoms.

Nineteen $(90.5 \%)$ of the patients with dyspepsia symptoms related the onset or worsening of the gastrointestinal symptoms with the ingestion of specific foods. The most common foods reported were: milk, bread and pasta, fried foods, red meat, banana and coffee. 
Table 1. Demographic and clinical characteristics of patients with DM1. Comparison of patients with and without dyspepsia

\begin{tabular}{|c|c|c|c|c|}
\hline Variables & $\begin{array}{c}\text { Total } \\
(n=32)\end{array}$ & $\begin{array}{l}\text { Patients with dyspepsia } \\
\qquad(\mathrm{n}=21)\end{array}$ & $\begin{array}{l}\text { Patients without dyspepsia } \\
\qquad(\mathrm{n}=11)\end{array}$ & $\mathbf{p}$ \\
\hline Age (years) & $38 \pm 9$ & $37 \pm 9$ & $41 \pm 7$ & 0.18 \\
\hline Sex: & & & & 1 \\
\hline Female ( $\mathrm{n} \%)$ & $25(78.1)$ & $16(76.2)$ & $9(81.8)$ & \\
\hline Male (n \%) & $7(21.9)$ & $5(23.8)$ & $2(18.2)$ & \\
\hline Time since diabetes diagnosis (years) & $22 \pm 5$ & $25 \pm 6$ & $21 \pm 5$ & 0.06 \\
\hline Peripheral neuropathy n (\%) & $15(46.9)$ & $10(47.6)$ & $5(45.4)$ & 1 \\
\hline Retinopathy (\%) & $28(87.5)$ & $17(81)$ & $11(100)$ & 0.27 \\
\hline Diabetic nephropathy n (\%) & $22(68.7)$ & $16(76.2)$ & $6(54.5)$ & 0.25 \\
\hline Smoking $n(\%)$ & $4(12.5)$ & $4(19)$ & $0(0)$ & 0.27 \\
\hline $\mathrm{HbA1c}(\%)$ & $9.1 \pm 1.7$ & $9.6 \pm 1.7$ & $8.2 \pm 1.3$ & 0.01 \\
\hline
\end{tabular}

Table 2. Frequency of gastrointestinal symptoms in patients with DM1 and in the control group

\begin{tabular}{lccc}
\hline Symptoms & $\begin{array}{c}\text { DM1 patients } \\
(\mathbf{n = 3 2})\end{array}$ & $\begin{array}{c}\text { Controls } \\
(\mathbf{n = 5 0 )}\end{array}$ & $\mathbf{p}$ \\
\hline Dysphagia & $6(18.7 \%)$ & $1(2 \%)$ & 0.01 \\
Heartburn and/or & $7(21.9 \%)$ & $3(6 \%)$ & 0.04 \\
regurgitation & & & \\
Postprandial fullness & $15(46.9 \%)$ & $5(10 \%)$ & 0.001 \\
Epigastralgia & $9(28.1 \%)$ & $11(22 \%)$ & 0.60 \\
Nausea/vomiting & $7(21.9 \%)$ & $3(6 \%)$ & 0.04 \\
Abdominal distention & $13(40.6 \%)$ & $8(16 \%)$ & 0.02 \\
Constipation & $9(28.1 \%)$ & $5(10 \%)$ & 0.04 \\
Diarrhea & $6(18.7 \%)$ & $0(0 \%)$ & 0.002 \\
Abdominal pain & $3(9.4 \%)$ & $1(2 \%)$ & 0.29 \\
Fecal incontinence & $5(15.6 \%)$ & $0(0 \%)$ & 0.01 \\
\hline
\end{tabular}

\section{Association between dyspeptic symptoms, glycemic control and diabetes complications}

Comparisons between diabetic patients with and without dyspepsia are shown in tables 1 and 3-5. Table 1 shows that diabetic patients with dyspepsia presented significantly higher levels of HbAlc when compared with diabetic patients without dyspepsia, indicating that this subgroup had worse glycemic control.

There was no statistical association $(\mathrm{p}>0.05)$ between dyspepsia symptoms and diabetes complications (peripheral neuropathy, retinopathy, nephropathy), or with any of the other parameters analyzed: sex, age, fasting glucose, creatinine values, creatinine clearance, and TSH.

\section{Upper digestive endoscopy findings}

UDE analysis showed that most of the patients with DMl (65.6\%) did not present relevant changes in the mucosa of the digestive system. The most important findings were severe erosive gastritis in two patients and a healing gastric ulcer in a patient. The comparison of patients with and without dyspepsia did not show significant differences in the frequency of endoscopic lesions.

\section{Helicobacter pylori infection}

H. pylori infection was found in eleven patients (34.4\%). The urease test and histological examination were in agreement in all cases. None of the patients reported previous treatment of the infection. There were no statistical differences between dyspeptic and asymptomatic patients as for the presence of the bacteria (Table 3 ).

\section{Presence of celiac disease}

Histological examination of the duodenal biopsies confirmed the diagnosis of celiac disease in one patient.

\section{Presence of anxiety and depression}

Thirty patients completed the HAD scale. According with the scores, 19 patients $(63.3 \%)$ presented some kind of mood alteration. Ten patients $(33.3 \%)$ presented anxiety associated with depression, 7 (23.3\%) showed only anxiety, and two (6.7\%) presented only depression.

There was no significant correlation $(\mathrm{p}>0,05)$ between the scores for anxiety and depression, HbAlc values and any other biochemical parameter. No statistically significant association was observed with gender, age, or diabetes complications, either.

Table 4 shows that $60 \%$ of the dyspeptic patients and $50 \%$ of the diabetic patients without symptoms of 
dyspepsia presented anxiety $(\mathrm{p}>0.05)$. On the other hand, depression was identified in $60 \%$ of the patients with dyspeptic complaints, whereas none of the diabetic without dyspepsia presented this disorder $(\mathrm{p}=$ $0.001)$. In accordance with these data, the score in the depression subscale was significantly greater in patients with dyspeptic symptoms.

\section{Association between dyspeptic symptoms and nutritional parameters}

Mean values of anthropometric parameters are presented in table 5. For the analysis of the results, the patient diagnosed with celiac disease was excluded, once she was malnourished. According to the BMI, 13 patients $(43.3 \%)$ were overweight and one $(3.3 \%)$ was obese.

When compared with patients without dyspeptic complaints, patients with dyspepsia presented significantly decreased values $(p<0.05)$ for the following parameters: BMI, waist circumference, and fat percentage.

There was no association between anthropometric data and any of the other clinical and laboratorial parameters analyzed. Besides, there was no statistical association between nutritional factors, anxiety and depres$\operatorname{sion}(\mathrm{p}>0.05)$.

\section{DISCUSSION}

Most of the studies that investigated gastrointestinal symptoms in DMl were carried out in groups that were mostly made up by patients with DM2 (3). Besides, the analysis of different study groups shows wide variability in terms of clinical and laboratory characteristics and length of the disease in patients with DMl. The advantage of the present study was to analyze dyspeptic symptoms in a homogenous group of patients with

Table 3. Lesions observed in upper digestive endoscopy and H. pylori infection in patients with type 1 diabetes and without dyspepsia

\begin{tabular}{|c|c|c|c|c|}
\hline Endoscopic alterations & $\begin{array}{c}\text { Total } \\
\mathrm{n}=32\end{array}$ & $\begin{array}{l}\text { Patients with dyspepsia } \\
(\mathrm{n}=20)\end{array}$ & $\begin{array}{l}\text { Patients without dyspepsia } \\
\qquad(\mathrm{n}=11)\end{array}$ & $\mathbf{p}$ \\
\hline Erosive lesions/peptic ulcer & $11(34.4 \%)$ & $8(38.1)$ & $3(27.3 \%)$ & 0.70 \\
\hline Mild erosive gastritis & 7 & 5 & 2 & \\
\hline Mild erosive gastritis + erosive esophagitis & 1 & 1 & 0 & \\
\hline \multicolumn{5}{|l|}{ Severe erosive gastritis } \\
\hline \multirow[t]{2}{*}{ Gastric ulcer } & 2 & 1 & 1 & \\
\hline & 1 & 1 & 0 & \\
\hline H. pylori infection & $11(34.4 \%)$ & $6(28.6 \%)$ & $5(45.4 \%)$ & 0.44 \\
\hline
\end{tabular}

Table 4. Anxiety and depression in patients with DM1 according to the HAD scale. Comparison between diabetic patients with and without dyspeptic symptoms

\begin{tabular}{lcccc}
\hline Mood alterations & $\begin{array}{c}\text { Total } \\
(\mathbf{n = 3 0 )}\end{array}$ & $\begin{array}{c}\text { Patients with dyspepsia } \\
(\mathbf{n = 2 0 )}\end{array}$ & $\begin{array}{c}\text { Patients without dyspepsia } \\
(\mathbf{n = 1 1 )}\end{array}$ & $\mathbf{p}$ \\
\hline Anxiety & $17(56.7 \%)$ & $12(60 \%)$ & $5(50 \%)$ & 0.70 \\
Anxiety score & $8.3 \pm 4.7$ & $9.1 \pm 5$ & $6.4 \pm 4.4$ & 0.20 \\
Depression & $12(40 \%)$ & $12(60 \%)$ & $0(0 \%)$ & 0.001 \\
Depression score & $6.9 \pm 4.3$ & $8.3 \pm 4.2$ & $4.0 \pm 3.0$ & 0.005 \\
\hline
\end{tabular}

Table 5. Anthropometric data of diabetic patients according to the presence or absence of dyspeptic symptoms

\begin{tabular}{|c|c|c|c|c|}
\hline Anthropometric data & $\begin{array}{c}\text { Total } \\
\left(\mathrm{n}=31^{\star}\right)\end{array}$ & $\begin{array}{l}\text { Patients with dyspepsia } \\
\qquad(\mathrm{n}=\mathbf{2 0})\end{array}$ & $\begin{array}{l}\text { Patients without dyspepsia } \\
\qquad(\mathrm{n}=11)\end{array}$ & $\mathbf{p}$ \\
\hline $\mathrm{BMI}\left(\mathrm{kg} / \mathrm{m}^{2}\right)$ & $25.3 \pm 3.8$ & $24.3 \pm 4.1$ & $27.2 \pm 2.6$ & 0.02 \\
\hline Body fat (\%) & $28.3 \pm 7.1$ & $26.6 \pm 6.2$ & $30.8 \pm 7.7$ & 0.04 \\
\hline Waist circumference (cm) & $81.5 \pm 8.6$ & $78.7 \pm 8$ & $85.8 \pm 8.1$ & 0.02 \\
\hline Arm circumference (cm) & $29.7 \pm 3.8$ & $28.4 \pm 3.8$ & $31.5 \pm 3$ & 0.08 \\
\hline Tricipital skinfold (mm) & $15.9 \pm 5.7$ & $14.6 \pm 5.9$ & $17.6 \pm 5.2$ & 0.14 \\
\hline Corrected arm muscle area $\left(\mathrm{cm}^{2}\right)$ & $42.7 \pm 12$ & $39.1 \pm 12.3$ & $47.8 \pm 10$ & 0.06 \\
\hline
\end{tabular}

* Patient with celiac disease excluded from the statistical analysis. 
DMl in relation to the length of the disease, the presence of diabetes complications, and even in terms of inadequate glycemic control.

Patients were characterized by the high frequency of gastrointestinal symptoms, which was significantly greater than that in the control group, confirming the results of previous studies that demonstrated that digestive symptoms are more frequent in diabetic patients compared with non-diabetic controls (1-3). However, it is important to observe that the prevalence of dyspeptic complaints observed in the present cases was higher than that reported in population studies, and cannot be generalized to the whole population of $\mathrm{DMl}$ patients. This may be due to the fact that the study protocol required upper endoscopy to be carried out. Therefore, it is possible that diabetic patients with dyspeptic complaints had more interest in taking part in the study, what may have increased the frequency of changes in the group studied. Similarly, the predominance of female patients may also be related with greater interest in taking part in the study, once previous observations demonstrated that gastrointestinal symptoms are more frequent in women than in men with DMl (2). Considering this possible bias, all statistical analyses considered a possible gender effect.

Upper endoscopy showed that a large number of the diabetic patients with dyspeptic symptoms did not show gastroduodenal lesions that could explain the clinical picture, indicating that other factors may be responsible for the digestive complaints in these patients.

Results presented here indicate that H. pylori infection is not related to the presence of dyspeptic symptoms, confirming recent literature data $(8,21)$. The infection was found in $34.4 \%$ of the patients, similar to another Brazilian study with DMl adolescent patients (22). However, this prevalence is lower than the one reported in a Brazilian population study involving blood donors, which was $65-70 \%$ for individuals in the same age group (23). It is also lower than that observed in patients with functional dyspepsia in a previous study carried out by our group, which demonstrated the presence of the bacterium in $65 \%$ of the cases (24). Data on the prevalence of $H$. pylori infection in $\mathrm{DMl}$ are contradictory. Some studies show greater prevalence than the one found in the controls, and others show similar prevalence (8). On the other hand, some authors reported lower frequency of infection in those patients that had the disease for a longer time, due to the repeated use of antibiotics (25). This may be the explanation for the relatively low proportion of infections by $H$. pylori in the group of diabetic patients in the present study: they may have been treated countless times with antibiotics during the prolonged course of their disease.

A large number of patients with DMl presented anxiety and/or depression disorders, confirming literature results $(13,14)$. Besides, an association between depression and dyspeptic symptoms in these patients was demonstrated. The relationship of gastrointestinal symptoms with anxiety and depression was already described in groups of DM1 and DM2 patients (15). This association was also documented in the follow-up of a mixed group of patients with DMl and DM2 during a period of two years. It was observed that the onset of depression symptoms increased three times the risk of gastrointestinal symptoms, no matter the type of diabetes (26).

The mechanisms responsible for the relationship between gastrointestinal symptoms and psychological factors have not been elucidated in diabetes, yet. One of the mechanisms proposed to explain this association in functional dyspepsia is visceral hypersensitivity, that is, an increased perception of gastrointestinal sensations $(27,28)$. It was demonstrated that anxiety and depression may influence the central processing of visceral stimuli, increasing the perception of gastrointestinal sensations (29). Gastrointestinal symptoms, on their turn, may increase the levels of anxiety and depression, leading to a vicious cycle. Once the studies on diabetes already demonstrated abnormalities in the perception of visceral sensations in different parts of the gastrointestinal tract (30), it may be inferred that, similar to what was observed in functional diseases, the relationship between psychological factors and gastrointestinal symptoms in diabetes may be explained, at least in part, by visceral hypersensitivity (15). This hypothesis still needs to be confirmed by new studies.

In spite of the fact that almost all diabetic patients in the study presented inadequate glycemic control, the levels of $\mathrm{HbAlc}$ were significantly higher in dyspeptic patients than in those without dyspepsia, suggesting a role of glycemic control in the production of dyspeptic symptoms in DMI. These results are in agreement with the observations of other authors $(2,31)$. Laboratory studies in which patients were submitted to gastric distention by means of the insufflation of intragastric balloons showed that severe hyperglycemia increases the perception of nausea and bloating (30-32), suggesting that visceral hypersensitivity may also be involved 
in the relationship between glycemic control and dyspeptic symptoms in DMl. New studies are necessary to explore this hypothesis.

According to the data presented here, there was no association between digestive symptoms and peripheral neuropathy or other diabetes complications. However, these results do not enable us to rule out the participation of autonomic neuropathy in the pathogenesis of dyspeptic symptoms, once the appropriate tests to investigate this change were not used in the present study. It is important to mention, however, that previous studies did not evidence good correlations between digestive symptoms and diabetic autonomic neuropathy, suggesting a multifactorial physiopathology for dyspepsia in these patients $(5,30)$. The results of the present study seem to fit the current view that digestive symptoms in DMl are result of a complex relationship between psychological changes, glycemic control, visceral hypersensitivity, and autonomic neuropathy $(15,33)$.

The evaluation of data on BMI in the studied group evidences a high percentage of overweight patients, confirming recent studies on DMl $(34,35)$. However, the values for nutritional parameters in dyspeptic patients were reduced compared with those observed in patients without dyspepsia, suggesting that digestive symptoms may influence the nutritional status of DMl patients. As patients related their digestive complaints with the ingestion of different foods, it is possible that food intake in these patients was reduced due to the severity of the symptoms, leading to the changes in nutritional status. This possible relationship should be adequately investigated in future studies.

In conclusion, dyspeptic symptoms may be associated with worse glycemic control and presence of depression, in most of the patients with DMl. Besides, dyspepsia seems to negatively affect the nutritional status of the diabetic patients. Therefore, it is important that the endocrinologist considers these symptoms and recognize that adequate treatment of digestive complaints also depends on the effective approach of psychosocial factors involved.

Disclosure: no potential conflict of interest relevant to this article was reported.

\section{REFERENCES}

1. Mjörnheim AC, Finizia C, Blohmé G, Attvall S, Lundell L, Ruth M. Gastrointestinal symptoms in type 1 diabetic patients, as compared to a general population - A questionnaire-based study. Digestion. 2003;68:102-8.
2. Schvarcz $E$, Palmér $M$, Ingberg $C M$, Aman J, Berne C. Increased prevalence of upper gastrointestinal symptoms in long-term type 1 diabetes mellitus. Diabetic Med. 1996;13:478-81.

3. Bytzer P, Talley NJ, Leemon M, Young LJ, Jones MP, Horowitz M. Prevalence of gastrointestinal symptoms associated with diabetes mellitus: a population-based survey of 15,000 adults. Arch Intern Med. 2001;161:1989-96.

4. Talley NJ, Young L, Bytzer P, Hammer J, Leemon M, Jones M, et al. Impact of chronic gastrointestinal symptoms in diabetes mellitus on health-related quality of life. Am J Gastroenterol. 2001;96:71-6.

5. Rodrigues ML, Motta ME. Mechanisms and factors associated with gastrointestinal symptoms in patients with diabetes mellitus. J Pediatr (Rio J). 2012;88:17-24.

6. Tseng PH, LeeYC, Chiu HM, Chen CC, Liao WC, Tu CH, et al. Association of diabetes and $\mathrm{HbA1c}$ levels with gastrointestinal manifestations. Diabetes Care. 2012;35:1053-60.

7. Holub JL, Silberg DG, Michaels LC, Williams JL, Morris CD, Eisen G. Acid-related upper endoscopy findings in patients with diabetes versus non-diabetic patients. Dig Dis Sci. 2010;55:2853-9.

8. Ojetti V, Migneco A, Silveri NG, Ghirlanda G, Gasbarrini G, Gasbarrini A. The role of $\mathrm{H}$. pylori infection in diabetes. Curr Diabetes Rev. 2005;1:343-7.

9. Kofod-Andersen K, Tarnow L. Prevalence of gastroparesis-related symptoms in an unselected cohort of patients with Type 1 diabetes. J Diabetes Complications. 2012;26:89-93.

10. Sfarti C, Trifan A, Hutanasu C, Cojocariu C, Singeap AM, Stanciu C. Prevalence of gastroparesis in type 1 diabetes mellitus and its relationship to dyspeptic symptoms. J Gastrointestin Liver Dis. 2010;19(3):279-84

11. Punkkinen J, Färkkilä M, Mätzke S, Korppi-TommolaT, Sane T, Piirilä $\mathrm{P}$, et al. Upper abdominal symptoms in patients with Type 1 diabetes: unrelated to impairment in gastric emptying caused by autonomic neuropathy. Diabetic Medicine. 2008;25:570-7.

12. Budavari Al, Olden KW. Psychosocial aspects of functional gastrointestinal disorders. Gastroenterol Clin North Am. 2003;32:477506.

13. Lloyd CE, Dyert PH, Barnett AH. Prevalence of symptoms of depression and anxiety in diabetics clinical population. Diabet Med. 2000;17:198-202.

14. Grigsby AB, Anderson RJ, Freedland KE, Clouse RE, Lustman PJ. Prevalence of anxiety in adults with diabetes: a systematic review. J Psychosom Res. 2002;53:1053-60.

15. Talley SJ, Bytzer P, Hammer J, Young L, Jones M, Horowitz M. Psychological distress is linked to gastrointestinal symptoms in diabetes mellitus. Am J Gastroenterol. 2001;96:1033-8.

16. American Diabetes Association (ADA). Diagnosis and classification of diabetes mellitus. Diabetes Care. 2008;31 Suppl 1:S55-60.

17. Reisswitz PS, Mazzoleni LE, Sander GB, Francisconi CF. Portuguese validation of the Rome III diagnostic questionnaire for functional dyspepsia. Arq Gastroenterol. 2010;47:354-60.

18. Volta U, Tovoli F, Caio G. Clinical and immunological features of celiac disease in patients with Type 1 diabetes mellitus. Expert Rev Gastroenterol Hepatol. 2011;5:479-87.

19. Botega NJ, Bio MR, Zomignani MA, et al. Mood disorders among medical inpatients: a validation study of the hospital anxiety and depression scale (HAD). Rev Saude Publica. 1995;29:355-63.

20. Durnin JVGA, Womersley J. Body fat assessed from total body density and its estimation from skinfold thickness: measurements on 481 men and women aged from 16 to 72 years. $\mathrm{Br} \mathrm{J}$ Nutr. 1974;32:77-97.

21. Xia HH, Talley NJ, Kam EP, Young LJ, Hammer J, Horowitz M. Helicobacter pylori infection is not associated with diabetes mellitus nor with upper gastrointestinal symptoms in diabetes mellitus. Am J Gastroenterol. 2001;96:1039-46. 
22. Cabral VL, Patrício FR, Gabbay MA, Dib SA, Miszputen SJ. Intraepithelial lymphocytes in duodenum from Brazilian adolescents with type 1 diabetes. Influence of Helicobacter pylori. Pediatr Diabetes. 2009;10:316-20.

23. Zaterka S, Eisig JN, Chinzon D, Rothstein W. Factors related to Helicobacter pylori prevalence in an adult population in Brazil. Helicobacter. 2007; 2:2-8.

24. Lorena SL, de Souza Almeida JR, Mesquita M. Orocecal transit time in patients with functional dyspepsia. J Clin Gastroenterol. 2002;35:21-4.

25. de Luis DA, de la Calle H, Roy G, de Argila CM, Valdezate S, Canton $R$, et al. Helicobacter pylori infection and insulin-dependent diabetes mellitus. Diabetes Res Clin Pract. 1998;39:143-6.

26. Quan C,Talley NJ, Jones MP, Spies J, Horowitz M. Gain and loss of gastrointestinal symptoms in diabetes mellitus: associations with psychiatric disease, glycemic control, and autonomic neuropathy over 2 years of follow-up. Am J Gastroenterol. 2008;103:2023-30.

27. Brun R, Kuo B. Functional dyspepsia. Ther Adv Gastroenterol. 2010;3:145-64.

28. Van Oudenhove L, Vandenberghe J, Geeraerts B, Vos R, Persoons $P$, Demyttenaere K, et al. Relationship between anxiety and gastric sensorimotor function in functional dyspepsia. Psychosom Med. 2007;69:455-63.
29. Elsenbruch S, Rosenberger C, Enck P, Forsting M, Schedlowski M, Gizewski ER. Affective disturbances modulate the neural processing of visceral pain stimuli in irritable bowel syndrome: an fMRI study. Gut. 2010;59:489-95.

30. Zhao J, Frokjaer JB, Drewes MA, Ejskjaer N. Upper gastrointestinal sensory-motor dysfunction in diabetes mellitus. World J Gastroenterol. 2006;12:2846-57.

31. Rayner CK, Samsom M, Jones KL, Horowitz M. Relationships of upper gastrointestinal motor and sensory function with glycemic control. Diabetes Care. 2001;24:371-81.

32. Hebbard GS, Sun WM, Dent J, Horowitz M. Hyperglycaemia affects proximal gastric motor and sensory function in normal subjects. Eur J Gastroenterol Hepatol. 1996;8:211-7.

33. Troncon LE, Lopes RP, Simão MN, Iquegami M, Rosa-e-Silva L, Nobree-Souza MA, et al. Frequência de sintomas digestivos em pacientes brasileiros com diabetes mellitus. Rev Assoc Med Bras. 2001;47(2):157-64.

34. Moraes CM, Portella RB, Pinheiro VS, Oliveira MMS, Fuks AG, Cunha EF, et al. Prevalência de sobrepeso e obesidade em pacientes com diabetes tipo 1. Arq Bras Endocrinol Metab. 2003;47:677-83.

35. Toeller M, Buyken AE, Heitkamp G, Cathelineau G, Ferriss B, Michel G; EURODIAB IDDM Complications Study Group: nutrient intakes as predictors of body weight in European people with type 1 diabetes. Int J Obes Relat Metab Disord. 2001;25:1815-22. 